\title{
Characteristics Associated with Accelerated Lung Function Decline in a Primary Care Population with Chronic Obstructive Pulmonary Disease
}

This article was published in the following Dove Press journal: International Journal of Chronic Obstructive Pulmonary Disease

\author{
Hannah R Whittaker ${ }^{\prime}$ \\ Jeanne M Pimenta ${ }^{2}$ \\ Deborah Jarvis $\mathbb{1}^{1}$ \\ Steven J Kiddle $\mathbb{D}^{3}$ \\ Jennifer K Quint (ID)
}

'Respiratory Epidemiology, Occupational Medicine and Public Health, National Heart and Lung Institute, Imperial College London, London, UK; ${ }^{2}$ Epidemiology (Value Evidence and Outcomes), GlaxoSmithKline, R\&D, Uxbridge, UK; ${ }^{3}$ MRC Biostatistics Unit, University of Cambridge, Cambridge, UK
Correspondence: Hannah R Whittaker Imperial College, Emmanuel Kaye Building, National Heart and Lung Institute, London, UK

Email h.whittaker@imperial.ac.uk
Background: Estimates for lung function decline in chronic obstructive pulmonary disease (COPD) have differed by study setting and have not been described in a UK primary care population.

Purpose: To describe rates of $\mathrm{FEV}_{1}$ and $\mathrm{FVC}$ decline in COPD and investigate characteristics associated with accelerated decline.

Patients and Methods: Current/ex-smoking COPD patients (35 years + ) who had at least 2 $\mathrm{FEV}_{1}$ or $\mathrm{FVC}$ measurements $\geq 6$ months apart were included using Clinical Practice Research Datalink. Patients were followed up for a maximum of 13 years. Accelerated rate of lung function decline was defined as the fastest quartile of decline using mixed linear regression, and association with baseline characteristics was investigated using logistic regression.

Results: A total of 72,683 and 50,649 COPD patients had at least $2 \mathrm{FEV}_{1}$ or FVC measurements, respectively. Median rates of $\mathrm{FEV}_{1}$ and $\mathrm{FVC}$ changes or decline were $-18.1 \mathrm{~mL} /$ year (IQR: -31.6 to -6.0 ) and $-22.7 \mathrm{~mL} /$ year (IQR: -39.9 to -6.7 ), respectively. Older age, high socioeconomic status, being underweight, high mMRC dyspnoea and frequent AECOPD or severe AECOPD were associated with an accelerated rate of $\mathrm{FEV}_{1}$ and FVC decline. Current smoking, mild airflow obstruction and inhaled corticosteroid treatment were additionally associated with accelerated $\mathrm{FEV}_{1}$ decline whilst women, sputum production and severe airflow obstruction were associated with accelerated FVC decline.

Conclusion: Rate of $\mathrm{FEV}_{1}$ and FVC decline was similar and showed similar heterogeneity. Whilst $\mathrm{FEV}_{1}$ and FVC shared associations with baseline characteristics, a few differences highlighted the importance of both lung function measures in COPD progression. We identified important characteristics that should be monitored for disease progression.

Keywords: pulmonary disease, chronic obstructive, spirometry, lung function

\section{Introduction}

Lung function decline is a hallmark of chronic obstructive pulmonary disease (COPD). Studies investigating the rate of lung function decline in people with COPD have shown that it is heterogeneous and dependent on various characteristics including smoking status, medication use, and emphysema. ${ }^{1}$ Rate of lung function decline has been investigated in various settings in people with COPD; however, the literature shows inconsistency of evidence depending on the setting.

Much of the literature to date has investigated the rate of forced expiratory volume in 1 second $\left(\mathrm{FEV}_{1}\right)$ in COPD. Previous randomised control trials (RCTs) have shown that the mean rate of $\mathrm{FEV}_{1}$ decline in COPD patients is around $-40 \mathrm{~mL} /$ year. $^{2-5}$ Most RCTs 
have strict inclusion and exclusion criteria, leading to inclusion of selected populations of COPD patients whose rates of decline may not be generalizable to the wider population of COPD patients. Recently, a study found that $2.3 \%$ to $46.7 \%$ of COPD patients in a French cohort would have met the eligibility criteria for 16 RCTs that aimed to investigate treatment on reducing AECOPD (mean eligibility rate 16.5\% [95\% CI 9.2-23.7]). ${ }^{6}$ Observational studies report an attenuated mean rate of $\mathrm{FEV}_{1}$ decline compared to those seen in RCTs. For example, the ECLIPSE study reported a mean $\mathrm{FEV}_{1}$ decline of $-33.2 \mathrm{~mL} /$ year in COPD patients aged 40 to 75 with a history of smoking. ${ }^{1}$ As with the ECLIPSE study, the BODE study found that rate of $\mathrm{FEV}_{1}$ decline in COPD patients was heterogeneous and approximately $82 \%$ of patients had a nonsignificant decline in $\mathrm{FEV}_{1}$ with a mean decline of $-28 \mathrm{~mL} /$ year. ${ }^{7}$ Further observational studies have found declines ranging from $-12.6 \mathrm{~mL} /$ year to $-27 \mathrm{~mL} /$ year in COPD patients. ${ }^{8,9}$

In terms of factors that are associated with rate of lung function decline, frequent or severe AECOPD have been identified as a main risk factor for accelerated decline, notably in RCTs. ${ }^{2,10,11}$ In addition, much of the data from RCTs have identified inhaled corticosteroids (ICS) as a type of COPD medication that reduces the rate of FEV $_{1}$ decline. ${ }^{12-14}$ Further characteristics that have been associated with lung function decline include higher age, lower baseline $\mathrm{FEV}_{1}$, current smoking status, and lower body mass index (BMI). ${ }^{2,11,15}$

Interestingly, only a few studies have investigated FVC decline in COPD patients. ${ }^{16}$ In people without COPD, cross-sectional studies have found low FVC to be associated with low BMI, respiratory symptoms and cardiovascular disease. ${ }^{17,18}$ FVC has been described longitudinally in populations without COPD but the rate of FVC decline in COPD patients is poorly described. ${ }^{19-22}$

The rate of lung function decline in a generalizable population of average, "real world" COPD patients who would be seen in primary care has not been described. In addition, few studies have looked at how comorbidities, as well as other clinical characteristics such as medication, symptoms, and patient demographics, influence the rate of lung function decline, as measured by both $\mathrm{FEV}_{1}$ and $\mathrm{FVC}$ in COPD patients in primary care.

\section{Patients and Methods}

\section{Study Population and Study Design}

Clinical Research Practice Datalink (CPRD-GOLD), an electronic healthcare record database which consists of
UK primary care data, was linked to Hospital Episode Statistics (HES). CPRD is a primary care database that holds information on patients from general practices (GPs) who have signed up to CPRD and is generalizable to the UK population in terms of age, sex, and ethnicity. ${ }^{23}$ HES consists of hospitals in England. Patients were included if they had been diagnosed with COPD using primary care diagnosis codes which had been previously validated. Further inclusion criteria required COPD patients to be current or ex-smokers, aged 35 or older, have at least two $\mathrm{FEV}_{1}$ or FVC measurements at least 6 months apart, and have linked HES data. We used a previously validated primary care COPD diagnosis code set for identification of COPD patients in CPRD with a PPV of $97.1 \%{ }^{24}$ Two study cohorts were created using either $\mathrm{FEV}_{1}$ or FVC measurements. Start of follow-up was from the first $\mathrm{FEV}_{1}$ or FVC measurement after: i) COPD diagnosis; ii) current GP registration date, ii) date at which data were deemed to be of research standard (up-to-standard); iii) the date at which they turned 35, or; iv) the 1st January 2004. End of follow-up was the 31st December 2017 or earlier if they died or left the GP. Figure 1 illustrates the study design for both $\mathrm{FEV}_{1}$ and FVC study cohorts.

\section{Exposure Variables}

Exposure variables were chosen a priori and were based on patient demographics, COPD-related symptoms, common comorbidities of COPD, COPD severity, and type of COPD medication which are all recorded in primary or secondary care and could influence patient's rate of lung function decline. See Supplementary materials for further details on definitions of baseline characteristics. Baseline patient demographics included age, gender, ethnicity, smoking status, and socioeconomic status measured using the Index of Multiple Deprivation (IMD) where 1 was the most deprived and 5 was the least deprived. COPD-related symptoms included self-reported or healthcare practitioner reported breathlessness, chronic cough, and sputum production. Baseline comorbidities included a history of myocardial infarction (MI), ischaemic stroke, lung cancer, bronchiectasis, heart failure (HF), gastrooesophageal reflux disease (GORD), anxiety, depression, asthma, and BMI categorised as normal weight (18.5$\left.25 \mathrm{~kg} / \mathrm{m}^{2}\right)$, underweight $\left(<18.5 \mathrm{~kg} / \mathrm{m}^{2}\right)$, overweight $(25-$ $\left.30 \mathrm{~kg} / \mathrm{m}^{2}\right)$, and obese $\left(\geq 30 \mathrm{~kg} / \mathrm{m}^{2}\right)$.COPD severity included modified MRC (mMRC) dyspnoea score and airflow obstruction categorised as mild ( $\geq 80 \%$ predicted), moderate $(50-80 \%$ predicted $)$, severe $(30-50 \%$ predicted $)$, and 


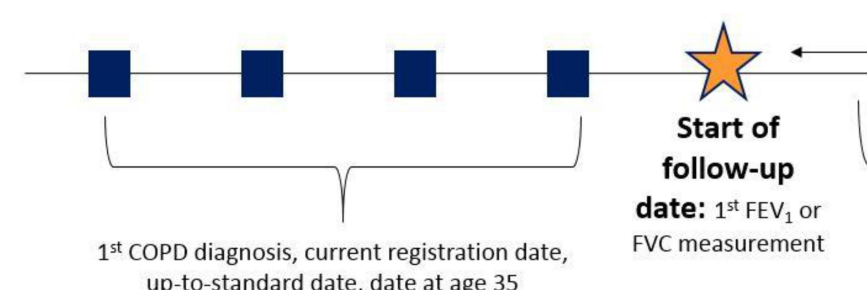

up-to-standard date, date at age 35 date: $1^{\text {st }} \mathrm{FEV}_{1}$ or

FVC measurement

\author{
(1)
}




\section{Results}

In this study, 72,683 COPD patients had at least $2 \mathrm{FEV}_{1}$ measurements at least 6 months apart and 50,649 patients had at least two FVC measurements at least 6 months apart. $68 \%$ of patients with serial $\mathrm{FEV}_{1}$ measurements also had at least 2 FVC measurements and $98 \%$ of patients with serial FVC measurements also had at least $2 \mathrm{FEV}_{1}$ measurements. Figure 2 illustrates the proportion of patients included. The median follow-up time in the $\mathrm{FEV}_{1}$ cohort was 5.8 years (IQR 3.6-8.5) and median number of $\mathrm{FEV}_{1}$ measurements over the study period was 4 (IQR 3-7). The median follow-up time in the FVC cohort was 5.7 years (IQR 3.6-8.4) and mean number of FVC measurements over the study period was 3 (IQR 2-5). Supplementary Figure E1 illustrates the distribution of the total number of spirometry measurements over patient follow-up. Table 1 highlights baseline characteristics for each cohort. Patients were similar in terms of all baseline characteristics other than cough, sputum, and breathlessness where patients in the FVC population had a higher proportion.

The median rate of $\mathrm{FEV}_{1}$ and $\mathrm{FVC}$ decline was $-18.1 \mathrm{~mL} /$ year (IQR: -31.6 to -6.0 ) and $-22.7 \mathrm{~mL} /$ year (IQR -39.9 to -6.7 ), respectively. Figure 3 illustrates the distribution of the change in $\mathrm{FEV}_{1}$ and $\mathrm{FVC}$ in $\mathrm{mL} /$ year in each cohort. After categorising patients into accelerated and non-accelerated lung function decline groups, 18,170 $(25 \%)$ of patients in the $\mathrm{FEV}_{1}$ cohort had accelerated $\mathrm{FEV}_{1}$ decline and 54,513 (75\%) had non-accelerated $\mathrm{FEV}_{1}$ decline. In the FVC cohort, 12,663 (25\%) had accelerated FVC decline and 37,986 (75\%) had nonaccelerated FVC decline.

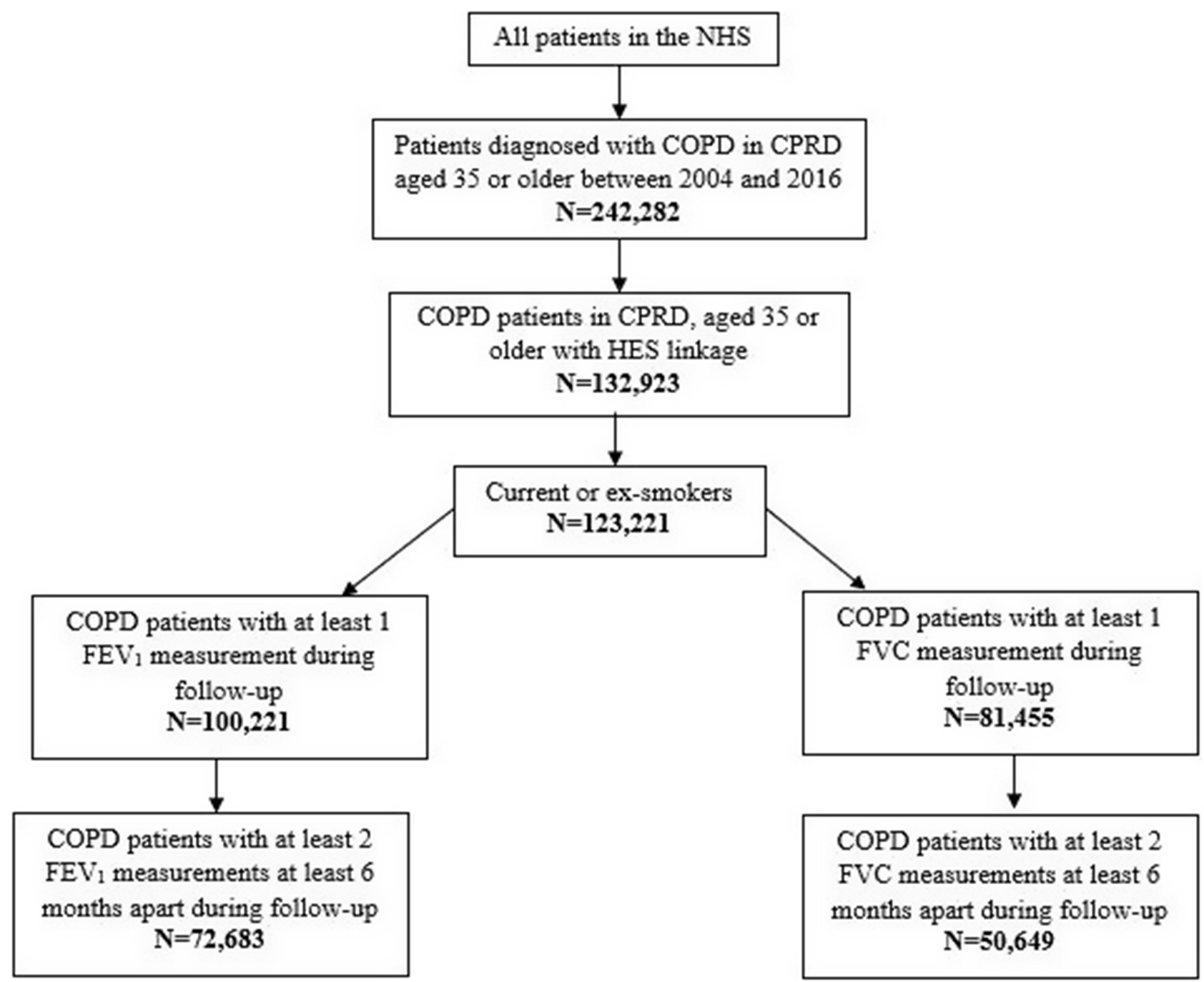

Figure 2 COPD patients included in the $\mathrm{FEV}_{\mathrm{I}}$ and FVC cohorts. 
Table I Baseline Characteristics of Study Participants in Both FEV, and FVC Cohorts

\begin{tabular}{|c|c|c|}
\hline $\begin{array}{l}\text { Baseline } \\
\text { Characteristics }\end{array}$ & $\begin{array}{l}\text { FEV, Cohort N (\%) } \\
\text { or Median (IQR) } \\
N=72,683\end{array}$ & $\begin{array}{l}\text { FVC Cohort N (\%) } \\
\text { or Median (IQR) } \\
N=50,649\end{array}$ \\
\hline \multicolumn{3}{|c|}{ Patient demographics } \\
\hline $\begin{array}{l}\text { Age } \\
\text { Gender (male) }\end{array}$ & $\begin{array}{l}67(60-75) \\
39,266(54.0)\end{array}$ & $\begin{array}{l}67(60-75) \\
27,389(54.1)\end{array}$ \\
\hline \multicolumn{3}{|l|}{ Smoking status } \\
\hline $\begin{array}{l}\text { Smoker } \\
\text { Ex-smokers }\end{array}$ & $\begin{array}{l}43,902(60.4) \\
26,781(39.6)\end{array}$ & $\begin{array}{l}30,584(60.4) \\
20,065 \text { (39.) }\end{array}$ \\
\hline \multicolumn{3}{|c|}{ Index of Multiple Deprivation* } \\
\hline $\begin{array}{l}\text { I (most } \\
\text { deprived) } \\
2 \\
3 \\
4 \\
5 \text { (least } \\
\text { deprived) }\end{array}$ & $\begin{array}{l}10,897(15.0) \\
13,700(18.9) \\
14,455(19.9) \\
16,085(22.1) \\
17,502(24.1)\end{array}$ & $\begin{array}{l}7327(14.5) \\
9375(18.5) \\
10,178(20.1) \\
11,398(22.5) \\
12,338(24.4)\end{array}$ \\
\hline \multicolumn{3}{|l|}{ Symptoms } \\
\hline $\begin{array}{l}\text { Breathlessness } \\
\text { Chronic cough } \\
\text { Sputum } \\
\text { production }\end{array}$ & $\begin{array}{l}11,997(16.5) \\
25,129(34.6) \\
5104(7.0)\end{array}$ & $\begin{array}{l}17,052(33.7) \\
28,997(57.3) \\
650 \mid(12.8)\end{array}$ \\
\hline \multicolumn{3}{|l|}{ Comorbidities } \\
\hline $\begin{array}{l}\text { Anxiety } \\
\text { Depression } \\
\text { GORD }\end{array}$ & $\begin{array}{l}5181(7.1) \\
5818(8.0) \\
3744(5.2)\end{array}$ & $\begin{array}{l}3763(7.4) \\
4015(7.9) \\
2715(5.4)\end{array}$ \\
\hline \multicolumn{3}{|l|}{ Body Mass Index * } \\
\hline $\begin{array}{l}\text { Underweight } \\
\text { Normal } \\
\text { Overweight } \\
\text { Obese } \\
\text { Bronchiectasis } \\
\text { Lung cancer } \\
\text { Heart failure } \\
\text { Stroke } \\
\text { Myocardial } \\
\text { infarction } \\
\text { Asthma }\end{array}$ & $\begin{array}{l}2353(4.1) \\
20,445(35.5) \\
20,017(34.8) \\
14,49(25.6) \\
1869(2.6) \\
348(0.5) \\
4532(6.2) \\
2757(3.8) \\
5030(6.9) \\
21,855(30.1)\end{array}$ & $\begin{array}{l}1908(4.1) \\
15,7 \mid 3(33.4) \\
16,165(34.4) \\
13,230(28.1) \\
1404(2.8) \\
237(0.5) \\
3086(6.1) \\
1818(3.6) \\
3506(6.9) \\
18,718(37.0)\end{array}$ \\
\hline \multicolumn{3}{|l|}{ COPD severity } \\
\hline \multicolumn{3}{|l|}{ mMRC dyspnoea* } \\
\hline $\begin{array}{l}0 \\
1 \\
2\end{array}$ & $\begin{array}{l}8098(20.8) \\
15,887(40.9) \\
9550(24.6)\end{array}$ & $\begin{array}{l}6252(20.7) \\
12,440(4 \mid .2) \\
74||(24.6)\end{array}$ \\
\hline
\end{tabular}

(Continued)
Table I (Continued).

\begin{tabular}{|c|c|c|}
\hline $\begin{array}{l}\text { Baseline } \\
\text { Characteristics }\end{array}$ & $\begin{array}{l}\text { FEV, Cohort N (\%) } \\
\text { or Median (IQR) } \\
\mathbf{N}=72,683\end{array}$ & $\begin{array}{l}\text { FVC Cohort N (\%) } \\
\text { or Median (IQR) } \\
\mathbf{N}=\mathbf{5 0 , 6 4 9}\end{array}$ \\
\hline 3 & $4533($ (II.7) & 3532 (11.7) \\
\hline 4 & $787(2.0)$ & $543(1.8)$ \\
\hline \multicolumn{3}{|c|}{ Airflow obstruction* } \\
\hline Mild & $18,267(25.4)$ & $13,398(27.2)$ \\
\hline Moderate & $33,452(46.5)$ & $22,663(46.0)$ \\
\hline Severe & $16,522(22.9)$ & $10,853(22.0)$ \\
\hline Very severe & $3777(5.2)$ & 2407 (4.9) \\
\hline \multicolumn{3}{|c|}{ AECOPD frequency in Ist year } \\
\hline None & $30,178(4 I .5)$ & $20,790(4 I .1)$ \\
\hline I moderate & $17,665(24.3)$ & $12,286(24.3)$ \\
\hline 2 moderate & $9618(13.2)$ & $6782(13.4)$ \\
\hline$\geq 3$ moderate & $11,339(15.6)$ & $8169(16.1)$ \\
\hline I severe, any & $3126(4.3)$ & $2127(4.2)$ \\
\hline moderate & & \\
\hline $\begin{array}{l}\quad \geq 2 \text { severe, any } \\
\text { moderate }\end{array}$ & $757(1.0)$ & $495(1.0)$ \\
\hline \multicolumn{3}{|l|}{ COPD medications } \\
\hline $\begin{array}{l}\text { ICS } \\
\text { combinations }\end{array}$ & $38,615(53.1)$ & $28,089(55.5)$ \\
\hline $\begin{array}{c}\text { Non-ICS } \\
\text { combinations }\end{array}$ & $34,068(46.9)$ & $22,560(44.5)$ \\
\hline $\begin{array}{l}\text { Mean first FEVI } \\
\text { or FVC in } L(S D)\end{array}$ & $1.7(0.7)$ & $2.7(\mathrm{I} .0)$ \\
\hline $\begin{array}{l}\text { Mean FEVI/FVC } \\
\text { ratio* }\end{array}$ & $0.6(0.7)$ & $0.6(0.7)$ \\
\hline
\end{tabular}

Notes: *IMD: FEV, cohort=49,279, FVC cohort=34,795; BMI: FEV, cohort $\mathrm{N}=57,564$, FVC cohort $\mathrm{N}=47,016$; MRC dyspnoea: $\mathrm{FEV}$, cohort $\mathrm{N}=38,855$, FVC cohort $\mathrm{N}=30,178$; Airflow obstruction $\mathrm{FEV}, \mathrm{N}=72,018$, FVC cohort $\mathrm{N}=49,321$; FEVI/FVC ratio: FEVI cohort $\mathrm{N}=49,601$, FVC cohort $\mathrm{N}=49,60$ I.

Abbreviations: GORD, gastro-oesophageal reflux disease; mMRC, modified Medical Research council; AECOPD, exacerbations of COPD; ICS, inhaled corticosteroid.

\section{Baseline Characteristics Associated with Accelerated Lung Function Decline}

Univariate analyses are described in Supplementary Table E1. In the multivariate analysis, compared to their reference categories, baseline characteristics significantly associated with accelerated $\mathrm{FEV}_{1}$ decline included older age $\left(\mathrm{OR}_{\text {adj }} 1.0195 \%\right.$ CI 1.00-1.01), current smoking status (OR ${ }_{\text {adj }} 1.15$ 95\% CI 1.07-1.23), high socioeconomic status $\left(\mathrm{OR}_{\text {adj }} 1.1595 \%\right.$ CI 1.04-1.27), breathlessness $\left(\mathrm{OR}_{\mathrm{adj}} 1.27\right.$ 95\% CI 1.15-1.39), high mMRC dyspnoea dyspnoea (mMRC 2: OR adj $1.1595 \%$ CI $1.05-1.27$; mMRC 3: 

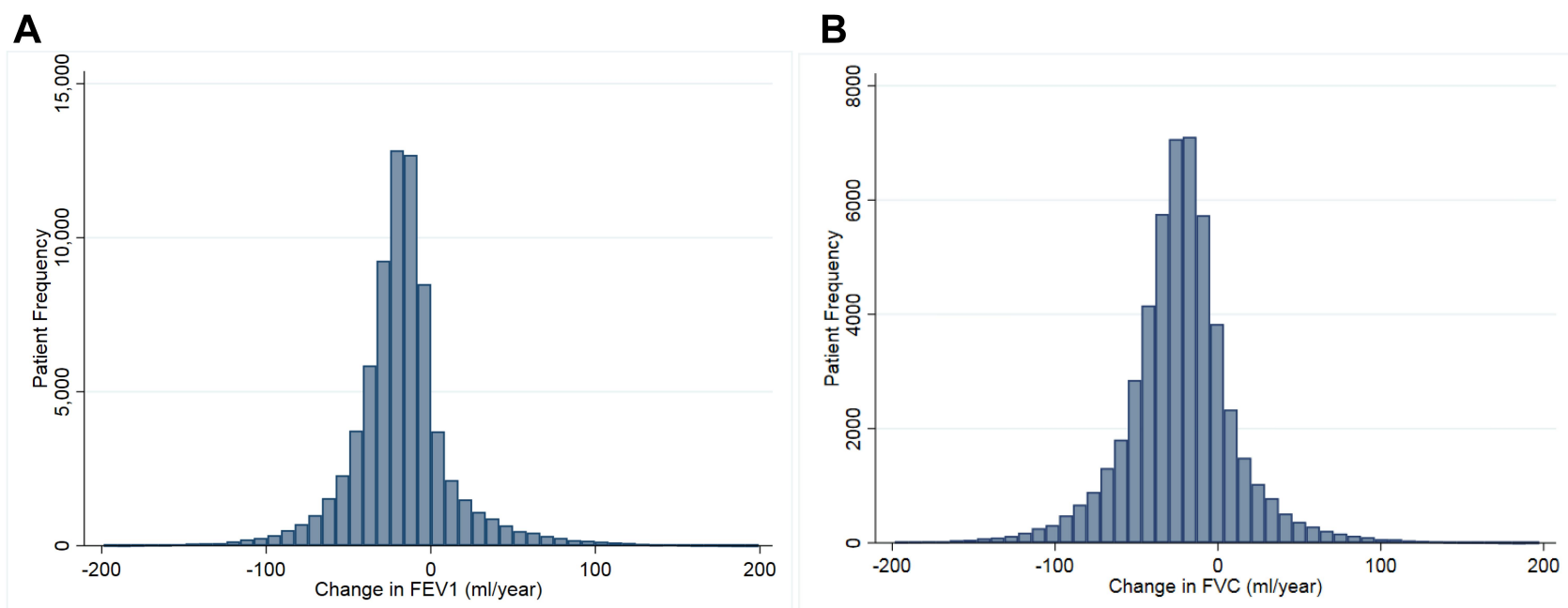

Figure 3 Distribution of the change in $\mathrm{FEV}_{\mathrm{I}}$ and $\mathrm{FVC}{ }^{\mathrm{I} .}$ 'Panel $(\mathbf{A})$ shows the distribution in the change in FEVI in 72,683 patients. Panel (B) shows the distribution in the change in FVC in 50,649 patients.

$\mathrm{OR}_{\text {adj }} 1.20$ 95\% CI 1.07-1.35), mild airflow obstruction reference group compared to moderate $\left(\mathrm{OR}_{\mathrm{adj}} 0.7495 \%\right.$ CI 0.67-0.81) and very severe (OR adj $0.6595 \%$ CI $0.47--$ 0.90), frequent AECOPD ( $\geq 3$ AECOPD OR adj $1.1895 \%$ CI 1.07-1.29) and being treated with inhaled corticosteroids (OR ${ }_{\text {adj }} 1.1195 \%$ CI 1.04-1.19) compared to reference categories (see Table 2).

Baseline characteristics significantly associated with accelerated FVC decline included older age $\left(\mathrm{OR}_{\mathrm{adj}} 1.03\right.$ 95\% CI 1.03-1.03), women (OR adj 0.48 95\% CI $0.45--$ $0.51)$, high socioeconomic status $\left(\mathrm{OR}_{\mathrm{adj}} 0.9895 \%\right.$ CI 0.90-1.07), cough (OR ${ }_{\text {adj }} 0.9195 \%$ CI 0.86-0.96), sputum production ( $\mathrm{OR}_{\mathrm{adj}} 1.13$ 95\% CI 1.05-1.22), history of heart failure $\left(\mathrm{OR}_{\mathrm{adj}} 1.1295 \%\right.$ CI 1.01-1.25), history of bronchiectasis $\left(\mathrm{OR}_{\mathrm{adj}} 1.1895 \%\right.$ CI 1.1-1.38), depression $\left(\mathrm{OR}_{\mathrm{adj}} 1.14\right.$ 95\% CI 1.03-1.25), being underweight $\left(\mathrm{OR}_{\mathrm{adj}}\right.$ 1.27 95\% CI 1.17-1.45), high mMRC dyspnoea (mMRC 2: $\mathrm{OR}_{\text {adj }} 1.23$ 95\% CI 1.14-1.33; mMRC 3: OR adj 1.30 95\% CI 1.18-1.43; mMRC 4: OR adj 1.39 95\% CI 1.14-1.70), severe airflow obstruction $\left(\mathrm{OR}_{\mathrm{adj}} 1.4795 \% \mathrm{CI} 1 .-\right.$ 27-1.70), and frequent AECOPD or AECOPD requiring hospitalisations ( $\geq 3$ moderate AECOPD: OR ${ }_{\text {adj }} 1.1595 \%$ CI 1.07-1.24; 1 severe AECOPD: OR adj $1.2895 \%$ CI $1.12-1.45$; $\geq 2$ severe AECOPD: OR ${ }_{\text {adj }} 1.55$ 95\% CI 1.19-2.02) compared to reference categories (see Table 2).

\section{Sensitivity Analyses}

Baseline characteristics associated with accelerated lung function decline were consistent across sensitivity analyses using the median rate of decline and $-40 \mathrm{~mL} / \mathrm{year}$ to define accelerated lung function decline (supplementary Tables E2-E3). High within patient variation was seen in our main $\mathrm{FEV}_{1}$ and $\mathrm{FVC}$ cohorts $(337 \mathrm{~mL}$ and $388 \mathrm{~mL}$, respectively) which led us to create sensitivity cohorts to reduce this variation. Patients included in the sensitivity cohorts were similar to our main study populations in terms of baseline characteristics; however, the sensitivity cohorts included fewer patients with severe airflow obstruction. Baseline characteristics associated with accelerated lung function decline remained consistent (Supplementary Tables E4-E6 and Supplementary Figure E2).

\section{Discussion}

This is the first study to describe the annual rate of lung function decline and to explore clinical and demographic patient characteristics associated with accelerated decline in a large primary care population of COPD patients over 13 years in England. $\mathrm{FEV}_{1}$ and $\mathrm{FVC}$ decline had similar median rates of decline and a similar degree of heterogeneity. Baseline characteristics that were consistently associated with accelerated $\mathrm{FEV}_{1}$ included older age, current smoking status, high socioeconomic status, being breathless and having a high mMRC dyspnoea, underweight, milder airflow obstruction, frequent AECOPD or AECOPD requiring hospitalisations, and being treated with ICS. Baseline characteristics that were consistently associated with accelerated FVC included older age, women, high socioeconomic status, sputum production, being underweight, high mMRC dyspnoea, severe airflow 
Table 2 Baseline Characteristics Associated with Accelerated Decline. Numbers are Adjusted OR (95\% Cl)

\begin{tabular}{|c|c|c|c|c|c|c|}
\hline & $\begin{array}{l}\text { Odds of Being } \\
\text { a Fast FEV, } \\
\text { Decliner (OR ( } 95 \% \\
\text { CI)) } N=30,609\end{array}$ & $P$ value & Test for Trend & $\begin{array}{l}\text { Odds of Being } \\
\text { a Fast FVC } \\
\text { Decliner (OR ( } 95 \% \\
\text { CI)) } N=28,02 \text { I }\end{array}$ & $P$ value & Test for Trend \\
\hline Age & $1.01(1.00-1.01)$ & 0.001 & & $1.03(1.03-1.03)$ & $<0.001$ & \\
\hline Gender (Males) & $0.91(0.83-1.00)$ & 0.050 & & $0.48(0.45-0.5 \mathrm{I})$ & $<0.001$ & \\
\hline Current smoking & $1.15(1.07-1.23)$ & $<0.001$ & & $1.03(0.98-1.09)$ & 0.268 & \\
\hline \multicolumn{7}{|l|}{ IMD } \\
\hline I (most deprived) & Ref & Ref & 0.015 & Ref & Ref & 0.016 \\
\hline 2 & $1.00(0.90-I . I I)$ & 0.976 & & $1.01(0.93-1.10)$ & 0.787 & \\
\hline 3 & $1.04(0.93-1.16)$ & 0.482 & & $0.98(0.90-1.07)$ & 0.609 & \\
\hline 4 & $1.01(0.91-1.12)$ & 0.878 & & $0.98(0.90-1.06)$ & 0.616 & \\
\hline 5 (least deprived) & $1.15(1.04-1.27)$ & 0.009 & & $1.15(1.06-1.25)$ & 0.001 & \\
\hline Breathlessness & $1.27(1.15-1.39)$ & $<0.001$ & & $1.03(0.98-1.09)$ & 0.248 & \\
\hline Cough & $1.07(0.99-1.16)$ & 0.079 & & $0.91(0.86-0.96)$ & 0.001 & \\
\hline Sputum & $1.06(0.92-1.21)$ & 0.424 & & $1.13(1.05-1.22)$ & 0.001 & \\
\hline Asthma & $0.93(0.86-1.01)$ & 0.079 & & $1.05(0.99-1.12)$ & 0.081 & \\
\hline Myocardial infarction & $0.94(0.84-1.06)$ & 0.311 & & $1.05(0.95-1.16)$ & 0.304 & \\
\hline Stroke & $1.10(0.95-1.28)$ & 0.206 & & $1.05(0.92-1.20)$ & 0.459 & \\
\hline Heart failure & $0.88(0.77-1.00)$ & 0.057 & & $1.12(1.01-1.25)$ & 0.036 & \\
\hline Lung cancer & $1.19(0.78-1.12)$ & 0.419 & & $0.95(0.66-1.36)$ & 0.786 & \\
\hline Bronchiectasis & $0.91(0.74-1.12)$ & 0.364 & & $1.18(1.01-1.38)$ & 0.036 & \\
\hline GORD & $0.96(0.84-1.10)$ & 0.552 & & $1.02(0.92-1.14)$ & 0.691 & \\
\hline Anxiety & $0.93(0.82-1.05)$ & 0.231 & & $1.07(0.97-1.19)$ & 0.169 & \\
\hline Depression & $1.09(0.97-I .22)$ & 0.150 & & $1.14(1.03-1.25)$ & 0.012 & \\
\hline \multicolumn{7}{|l|}{ Body mass index } \\
\hline Normal & Ref & Ref & $<0.001$ & Ref & Ref & $<0.001$ \\
\hline Underweight & I.16 (0.98-I.37) & 0.084 & & $1.27(1.17-1.45)$ & $<0.001$ & \\
\hline Overweight & $0.85(0.79-0.91)$ & $<0.001$ & & $0.89(0.84-0.95)$ & $<0.001$ & \\
\hline Obese & $0.84(0.78-0.91)$ & $<0.001$ & & $0.90(0.84-0.96)$ & 0.001 & \\
\hline \multicolumn{7}{|l|}{ mMRC } \\
\hline 0 & Ref & Ref & 0.947 & Ref & Ref & 0.556 \\
\hline I & $\mathrm{I} .02(0.94-\mathrm{I} . \mathrm{II})$ & 0.676 & & $1.06(0.99-1.13)$ & 0.107 & \\
\hline 2 & 1.15 (1.05-1.27) & 0.003 & & $1.23(1.14-1.33)$ & $<0.001$ & \\
\hline 3 & $1.20(1.07-1.35)$ & 0.003 & & $1.30(1.18-1.43)$ & $<0.001$ & \\
\hline 4 & I.I5 (0.90-I.48) & 0.272 & & $1.39(1.14-1.70)$ & 0.001 & \\
\hline \multicolumn{7}{|l|}{ Airflow obstruction } \\
\hline Mild & Ref & Ref & $<0.001$ & Ref & Ref & $<0.001$ \\
\hline Moderate & $0.74(0.67-0.81)$ & $<0.001$ & & $1.07(1.01-1.14)$ & 0.031 & \\
\hline Severe & 0.91 (0.77-I.07) & 0.232 & & $1.19(1.10-1.29)$ & $<0.001$ & \\
\hline Very severe & $0.65(0.47-0.90)$ & 0.010 & & $1.47(1.27-1.69)$ & $<0.001$ & \\
\hline \multicolumn{7}{|l|}{ AECOPD frequency } \\
\hline 0 & Ref & Ref & 0.001 & Ref & Ref & 0.188 \\
\hline I moderate, 0 severe & $1.04(0.96-1.12)$ & 0.322 & & $1.07(1.01-1.14)$ & 0.028 & \\
\hline 2 moderate, 0 severe & $1.09(0.99-1.20)$ & 0.079 & & $1.03(0.95-1.12)$ & 0.443 & \\
\hline$\geq 3$ moderate, 0 severe & I.18 (I.07-I.29) & 0.001 & & $1.15(1.07-1.24)$ & $<0.001$ & \\
\hline
\end{tabular}

(Continued) 
Table 2 (Continued).

\begin{tabular}{|c|c|c|c|c|c|c|}
\hline & $\begin{array}{l}\text { Odds of Being } \\
\text { a Fast FEV } \\
\text { Decliner (OR ( } 95 \% \\
\text { Cl)) } N=30,609\end{array}$ & $P$ value & Test for Trend & $\begin{array}{l}\text { Odds of Being } \\
\text { a Fast FVC } \\
\text { Decliner (OR ( } 95 \% \\
\text { CI)) } N=\mathbf{2 8 , 0 2 I}\end{array}$ & $P$ value & Test for Trend \\
\hline $\begin{array}{l}\text { I severe, any moderate } \\
\geq 2 \text { severe, any moderate }\end{array}$ & $\begin{array}{l}1.10(0.93-1.29) \\
1.11(0.77-1.60)\end{array}$ & $\begin{array}{l}0.277 \\
0.576\end{array}$ & & $\begin{array}{l}1.28(1.12-1.45) \\
1.55(1.19-2.02)\end{array}$ & $\begin{array}{l}<0.001 \\
0.001\end{array}$ & \\
\hline \multicolumn{7}{|l|}{ COPD medication } \\
\hline $\begin{array}{l}\text { Non-ICS combinations } \\
\text { ICS-combinations }\end{array}$ & $\begin{array}{l}\text { Ref } \\
\text { I.II (1.04-1.19) }\end{array}$ & $\begin{array}{l}\text { Ref } \\
0.002\end{array}$ & & $\begin{array}{l}\text { Ref } \\
1.04(0.99-1.10)\end{array}$ & $\begin{array}{l}\text { Ref } \\
0.142\end{array}$ & \\
\hline
\end{tabular}

Notes: For variables breathless, cough, sputum, asthma, MI, stroke, HF, lung cancer, bronchiectasis, GORD, anxiety and depression, the reference groups are not having the symptom/comorbidity. For smoking status, the reference group is ex-smoking patients.

Abbreviations: IMD, Index of Multiple Deprivation; GORD, gastro-oesophageal reflux disease; mMRC, modified Medical Research council; AECOPD, exacerbations of COPD; ICS, inhaled corticosteroid.

obstruction, and frequent AECOPD or AECOPD requiring hospitalisation. In addition, we found that patient characteristics included in this study accounted for approximately $18-20 \%$ of the variation of $\mathrm{FEV}_{1}$ and $\mathrm{FVC}$ decline, respectively.

\section{Rates of Decline in Previous Studies}

Previous studies have shown that rate of $\mathrm{FEV}_{1}$ decline is heterogeneous in COPD. The ECLIPSE study showed that change in $\mathrm{FEV}_{1}$ varied from declines faster than $-100 \mathrm{~mL} /$ year to increases greater than $100 \mathrm{~mL} /$ year. ${ }^{1}$ The ECLIPSE study, a non-interventional, multicentre observational study, collected lung function measurements at regular intervals. Using electronic healthcare records (EHR) we found similar distributions in the change in $\mathrm{FEV}_{1}$ in a primary care population in England highlighting the usefulness of using routinely collected data for research.

To date, RCTs are the gold standard in scientific research and are used to direct clinical guidelines. Mean rates of lung function decline in COPD RCTs are generally faster than the rates described in this study and some other observational studies. ${ }^{16,32,33}$ The Study to Understand Mortality and Morbidity in COPD Trial (SUMMIT) reported mean $\mathrm{FEV}_{1}$ declines between $-37 \mathrm{~mL} /$ year to $-47 \mathrm{~mL} /$ year depending on the treatment arm. ${ }^{34}$ Similarly, mean rates of $\mathrm{FEV}_{1}$ decline from the understanding potential long-term impacts on function with tiotropium (UPLIFT) study were $-43.9 \mathrm{~mL} /$ year (SE:1.41) in COPD patients on tiotropium and $-45.1 \mathrm{~mL} /$ year (SE1:45) in patients on placebo. ${ }^{3}$ Patients included in RCTs are not generalizable to the wider population due to strict inclusion and exclusion criteria such as requiring patients to have moderate or severe COPD, heightened risk of CVD, and specific number of pack-years smoking. ${ }^{3,12}$ Therefore, it is likely that differences in lung function decline will exist between RCT and observational populations. This highlights the need for incorporating observational studies in clinical guidelines.

Interestingly, there are previous observational studies that have found faster mean rate of $\mathrm{FEV}_{1}$ decline compared to those seen in our study. Luoto et al found that the mean absolute decline in $\mathrm{FEV}_{1}$ in a general population of people age 60 to 100 years old was $-51.7 \mathrm{~mL} /$ year $(95 \% \mathrm{CI}-63.7$ to -39.9$)$ and $-56.2 \mathrm{~mL} /$ year $(95 \%$ CI -73.6 to -38.8 ) for FVC. ${ }^{19}$ A possible explanation for this is that healthy patients have a higher baseline $\mathrm{FEV}_{1}$ or $\mathrm{FVC}$ and therefore, can lose more lung function than those who have lower lung function to start with. ${ }^{30}$ For example, the mean baseline $\mathrm{FEV}_{1}$ in health participants in the general population study was $2.37 \mathrm{~L}$ (SD 0.86) compared to $1.7 \mathrm{~L}$ (SD 0.7) in our COPD cohort.

In terms of FVC decline, most studies have described the rate of FVC decline in general populations and few studies have described the rate in COPD populations. Lee et al reported FVC declines in COPD patients from hospitals in Seoul in relation to tiotropium treatment. Patients treated with tiotropium averaged an FVC decline of $-55.1 \mathrm{~mL} /$ year compared to $-43.5 \mathrm{~mL} /$ year in control patients. ${ }^{35}$ This population differed as COPD patients 
were included if they had few comorbidities and the population largely consisted of men.

\section{Characteristics Associated with Accelerated Lung Function Decline Age and Smoking Status}

Age and smoking status are well-known risk factors of lung function decline and have been described in many previous studies of COPD populations and general populations. $^{21,36,37}$ It is important to highlight that we excluded never smokers in case of misdiagnosis of asthma with COPD. Interestingly, smoking status was not associated with rate of FVC decline. This is consistent with previous studies that found no association between smoking status and rate of FVC decline in the general population and in COPD populations. ${ }^{19,38,39}$

\section{ICS}

Interestingly, we found that patients on ICS-containing medications were more likely to have accelerated $\mathrm{FEV}_{1}$ decline. Many RCTs have investigated the relationship between ICS and lung function in COPD and results have shown that patients on ICS have attenuated rate of $\mathrm{FEV}_{1}$ decline compared to non-ICS treatments. ${ }^{4,5}$ SUMMIT, a large RCT, found that over approximately 2 years, patients on combined fluticasone furoate/vilanterol declined $10 \mathrm{~mL} /$ year slower than patients on vilanterol alone or placebo. ${ }^{12}$ Our study found the opposite effect whereby patients on ICS were more likely to have accelerated $\mathrm{FEV}_{1}$ decline compared to those on non-ICScontaining medication. It is highly likley that this due to confounding by indication whereby patients with faster disease progression who are more symptomatic are more likely prescribed ICS.

\section{Sex}

The literature on lung function decline by sex is inconsistent, but we showed that women were more likely to have accelerated FVC decline and similar odds of accelerated $\mathrm{FEV}_{1}$ decline to men. ${ }^{19,40}$ We adjusted for lung function at baseline in order to account for biological differences in airway size. ${ }^{41}$ Previous studies suggest that women have faster relative lung function decline compared to men. ${ }^{19,30}$ It is thought that women may be more responsive to tobacco smoke; however, we found no significant interaction between gender and smoking status. ${ }^{42}$ Other studies suggest that sex differences may exist due to differences in hormones and the presentation and progression of COPD. ${ }^{41,43}$

\section{mMRC Dyspnoea and Breathlessness}

Interestingly, higher MRC dyspnoea score and being breathless were associated with accelerated lung function decline. Previous cross-sectional studies have shown that $\mathrm{FEV}_{1}$ and MRC score are not associated; however, longitudinally MRC dyspnoea score may be a good predictor of accelerated lung function decline. ${ }^{44}$ Currently, NICE guidelines recommend various clinical characteristics such as spirometry, AECOPD frequency, and smoking status to be used to assess COPD progression. ${ }^{45}$ Whilst these are all important in assessing lung function progression, breathlessness should also be considered in assessing lung function progression. This may be a more important marker of lung function progression compared to spirometry given the association with airflow obstruction seen in this study.

\section{Airflow Obstruction}

Patients with milder COPD were more likely to have accelerated $\mathrm{FEV}_{1}$ decline compared to those with severe disease, which is in keeping with previous literature. ${ }^{46}$ Patients with milder disease may have higher baseline lung function and are able to lose more lung function than those with severe disease. ${ }^{30}$ In terms of FVC decline, we found that patients with severe airflow obstruction were more likely to have accelerated decline. There is limited research on the factors associated with the rate of FVC decline in a COPD population; however, it is possible that older patients with increased airflow obstruction develop fibrosis of the lungs resulting in the loss of FVC. ${ }^{47}$ In addition, given that mortality is associated with low FVC and increased obstruction, it is possible that patients with severe obstruction with a higher risk of mortality are more likely to lose FVC faster at this stage. ${ }^{48,49}$ Another possible explanation is that patients lose $\mathrm{FEV}_{1}$ faster in earlier disease stages and FVC consequently declines faster in later disease stages. A faster decline in $\mathrm{FEV}_{1}$ in earlier stages of COPD would drive the progression of obstruction and disease severity.

\section{AECOPD Frequency}

We found that frequent AECOPD and AECOPD requiring hospitalisations were associated with accelerated $\mathrm{FEV}_{1}$ and FVC decline which is in line with previous studies showing that both moderate and severe AECOPD 
influence $\mathrm{FEV}_{1}$ decline. ${ }^{2,8,10,11,50}$ However, only a few studies have investigated the association between AECOPD and rate of FVC decline. In a retrospective cohort of patients who were admitted to hospital for an AECOPD, FVC was lower during hospitalisation compared to 4 weeks after the hospitalisation. ${ }^{51}$ In addition, a previous study showed that FVC was lower during an AECOPD compared to before an AECOPD. Interestingly, the absolute decrease in FVC was greater than that in $\mathrm{FEV}_{1}$ at the time of AECOPD. ${ }^{52}$

\section{BMI}

Patients with low BMI are more likely to decline faster whilst patients with higher BMI are more likely to have slower lung function decline. ${ }^{19,40}$ A previous metaanalysis of RCTs investigating BMI and rate of $\mathrm{FEV}_{1}$ decline found that low BMI was associated with faster $\mathrm{FEV}_{1}$ decline in COPD patients. ${ }^{53}$ It is suggested that this relationship may be driven by reverse causation whereby severe COPD could result in increased weight loss. Therefore, overweight and obese patients appear to have slower rate of lung function decline, which is consistent with the "obesity paradox". ${ }^{4,55}$

\section{Sputum}

Sputum has previously been associated with accelerated lung function decline in COPD over a maximum of 12 years. ${ }^{56}$ Sputum production is used to characterise chronic bronchitis. Studies have shown that people with chronic bronchitis are more likely to decline faster than those without bronchitis. ${ }^{57}$

\section{High Socioeconomic Status}

Previous studies have shown that patients with low socioeconomic status are more likely to decline faster than those with higher socioeconomic status. ${ }^{58-60}$ Reasons for this association are not quite understood; however, it is possible that environmental, parental, and occupational exposures play a role. However, we found that patients with high socioeconomic status were more likely to have accelerated lung function decline. Previous studies have largely consisted of cross-sectional studies and inconsistencies exist between definitions of socioeconomic deprivation. $^{59}$ We used IMD which is a composite weighted score based on deprivation measures for small areas across England and includes income, employment, education, disability, crime, housing services, and environmental deprivation. It is possible that IMD may be imprecise as this is an area level marker of deprivation not an individual marker of deprivation.

\section{Strengths and Limitations}

This is the first study to describe the rate of lung function decline in a primary care COPD population and investigate baseline characteristics associated with accelerated decline. Overall, our study has not only highlighted wellknown characteristics, emphasising the quality and usefulness of EHR, but has shed light on other characteristics that were associated with accelerated lung function and may be useful in assessing COPD progression in clinical practice. A main strength of this study is that we found similar patterns of lung function decline to that of the ECLIPSE study. This highlights the usefulness of using routinely collected EHR in clinical research. A further strength of routinely collected data is that it allows large sample sizes and includes more realistic patients seen in everyday primary care practice than would be achievable in a RCT.

A limitation of this work is that $\mathrm{FEV}_{1}$ in primary care should be taken every 15 months in patients with COPD; however, the number and time between measurements in real practice varies. In addition, the increase in $\mathrm{FEV}_{1}$ and FVC in severe COPD patients could be due to survival bias as patients with very severe obstruction are more likely to die. Patients needed at least 2 lung function measurements at least 6 months apart and severe patients are more likely to be those who have survived to the inclusion date. Lung function decline in these patients may not representative of severe COPD patients. It is also possible that time-varying variables such as medication use, BMI, AECOPDs, and new comorbidities could have influenced recorded spirometry measurements during follow-up. In clinical practice, patients would be seen during a consultation and decisions could be made based on observations presented at that time. For this reason, we chose to investigate baseline characteristics, at one time point, and the association between accelerated lung function decline. Furthermore, only absolute change in lung function was assessed as this is commonly used to make judgement decisions in primary care. Whilst our study accounted for height, age, gender, and initial lung function, further studies should describe the change in relative lung function. Similarly, dichotomous rate of lung function was used as this may be a more meaningful outcome for decision making in primary care. Airflow obstruction was defined using $\mathrm{FEV}_{1 \%}$ predicted; however, our definition 
did not require patients to have an $\mathrm{FEV}_{1} / \mathrm{FVC}$ less than $70 \%$ due to the lack of recorded FVC in CPRD. Despite this, we used a validation definition of COPD that used clinical codes and only included smokers and exsmokers. ${ }^{24}$ In addition, it is possible that COPD patients received an asthma diagnosis after their COPD diagnosis which could have affected lung function variation; however, this percentage of patients is likely to be $14 \%$ or less. ${ }^{61,62}$ Finally, it is possible that the rate of FVC decline could have been impacted by gas trapping; however, hyperinflation or gas trapping information is not available in CPRD. ${ }^{63}$

\section{Conclusion}

This was the first study to describe the rate of lung function decline in a primary care population of COPD patients in England. Older age, high socioeconomic status, being underweight, high mMRC dyspnoea and frequent AECOPD or AECOPD requiring hospitalisations were associated with an accelerated rate of $\mathrm{FEV}_{1}$ and $\mathrm{FVC}$ decline. Current smoking status, breathlessness, mild airflow obstruction and being treated with inhaled corticosteroids were additionally associated with accelerated $\mathrm{FEV}_{1}$ decline whilst women, sputum production and severe airflow obstruction were associated with accelerated FVC decline. $\mathrm{FEV}_{1}$ and $\mathrm{FVC}$ declined at a similar rate in a population of COPD patients and change in lung function was heterogeneous, suggesting a wide range of COPD phenotypes.

\section{Data Sharing Statement}

Data are available on request from the Clinical Practice Research Datalink (CPRD). Their provision requires the purchase of a license and our license does not permit us to make them publicly available to all. We used data from the version collected in January 2018 and have clearly specified the data selected in our Methods section. To allow identical data to be obtained by others, via the purchase of a license, we will provide the code lists on request. Licences are available from the CPRD (http://www.cprd. com): The Clinical Practice Research Datalink Group, The Medicines and Healthcare products Regulatory Agency, 10 South Colonnade, Canary Wharf, London E14 4PU.

\section{Acknowledgments}

The protocol for this research was approved by the Independent Scientific Advisory Committee (ISAC) for MHRA Database Research (protocol number
18_249R) and the approved protocol was made available to the journal and reviewers during peer review. This study is based in part on data from the Clinical Practice Research Datalink obtained under licence from the UK Medicines and Healthcare products Regulatory Agency. The data is provided by patients and collected by the NHS as part of their care and support. The interpretation and conclusions contained in this study are those of the author/s alone. Linked pseudonymised data was provided for this study by CPRD. Secondary care data are linked to primary care data by NHS Digital, the statutory trusted third party for linkage, using identifiable data held only by NHS Digital. Select general practices in England consent to this process at a practice level with individual patients having the right to opt-out. This study is based in part on data from the Clinical Practice Research Datalink (CPRD) obtained under licence from the UK Medicines and Healthcare products Regulatory Agency. The data is provided by patients and collected by the National Health Service (NHS) as part of their care and support. The Office for National Statistics (ONS) was the provider of the ONS Data contained within the CPRD Data and maintains a Copyright (C) 2019, reused with the permission of The Health \& Social Care Information Centre, all rights reserved. The interpretation and conclusions contained in this study are those of the authors alone. This research was supported by the NIHR Imperial Biomedical Research Centre (BRC). The views expressed are those of the author(s) and not necessarily those of the NIHR or the Department of Health and Social Care. Steven J Kiddle and Jennifer K Quint are co-last authors for this study.

\section{Funding}

This manuscript was funded by GSK; study number 209427.

\section{Disclosure}

HRW \& JKQ received funding from GSK for this work. JKQ also reports grants from Asthma UK, personal fees from AZ, MRC, Chiesi, BI, and The Health Foundation, outside the submitted work. JMP is a full-time employee of GSK and holds shares in GSK. SJK reports personal fees from DIADEM and AstraZeneca, outside the submitted work. The authors report no other conflicts of interest in this work. 


\section{References}

1. Vestbo J, Edwards LD, Scanlon PD, et al. Changes in forced expiratory volume in 1 second over time in COPD. $N$ Engl J Med. 2011;365 (13):1184-1192. doi:10.1056/NEJMoa1105482

2. Halpin DMG, Decramer M, Celli BR, et al. Effect of a single exacerbation on decline in lung function in COPD. Respir Med. 2017;128:85-91. doi:10.1016/j.rmed.2017.04.013

3. Tashkin DP, Li N, Halpin D, et al. Annual rates of change in pre- vs. post-bronchodilator FEV1 and FVC over 4 years in moderate to very severe COPD. Respir Med. 2013;107(12):1904-1911. doi:10.1016/j. rmed.2013.08.001

4. Calverley PMA, Anderson JA, Brook RD, et al. Fluticasone furoate, vilanterol, and lung function decline in patients with moderate chronic obstructive pulmonary disease and heightened cardiovascular risk. Am J Respir Crit Care Med. 2018;197(1):47-55. doi:10.1164/ rccm.201610-2086OC

5. Burge PS, Calverley PM, Jones PW, et al. Randomised, double blind, placebo controlled study of fluticasone propionate in patients with moderate to severe chronic obstructive pulmonary disease: the ISOLDE trial. Br Med J. 2000;320(7245):1297-1303. doi:10.1136/ bmj.320.7245.1297

6. Pahus L, Burgel P-R, Roche N, et al. Randomized controlled trials of pharmacological treatments to prevent COPD exacerbations: applicability to real-life patients. BMC Pulm Med. 2019;19(1):127. doi:10.1186/s12890-019-0882-y

7. Casanova C, de Torres JP, Aguirre-Jaíme A, et al. The progression of chronic obstructive pulmonary disease is heterogeneous: the experience of the BODE cohort. Am J Respir Crit Care Med. 2011;184 (9):1015-1021. doi:10.1164/rccm.201105-0831OC

8. Pérez-Padilla R, Fernandez-Plata R, Montes de Oca M, et al. Lung function decline in subjects with and without COPD in a population-based cohort in Latin-America. PLoS One. 2017;12(5): e0177032-e0177032. doi:10.1371/journal.pone.0177032

9. Kim SJ, Lee J, Park YS, et al. Age-related annual decline of lung function in patients with COPD. Int J Chron Obstruct Pulmon Dis. 2015;11:51-60. doi:10.2147/COPD.S95028

10. Dransfield MT, Kunisaki KM, Strand MJ, et al. Acute exacerbations and lung function loss in smokers with and without chronic obstructive pulmonary disease. Am J Respir Crit Care Med. 2017;195 (3):324-330.

11. Donaldson GC, Seemungal TA, Bhowmik A, Wedzicha JA. Relationship between exacerbation frequency and lung function decline in chronic obstructive pulmonary disease. Thorax. 2002;57 (10):847-852. doi:10.1136/thorax.57.10.847

12. Calverley PM, Anderson JA, Brook RD, et al. Fluticasone furoate, vilanterol and lung function decline in patients with moderate COPD and heightened cardiovascular risk. Am J Respir Crit Care Med. 2017;197(1):47-55.

13. Calverley PMA, Spencer S, Willits L, et al. Withdrawal from treatment as an outcome in the ISOLDE Study of COPD. Chest. 2003;124 (4):1350-1356. doi:10.1378/chest.124.4.1350

14. Pauwels RA, Löfdahl C-G, Laitinen LA, et al. Long-term treatment with inhaled budesonide in persons with mild chronic obstructive pulmonary disease who continue smoking. European Respiratory Society study on chronic obstructive pulmonary disease. N Engl J Med. 1999;340 (25):1948-1953. doi:10.1056/NEJM199906243402503

15. Abramson MJ, Kaushik S, Benke G, et al. Symptoms and lung function decline in a middle-aged cohort of males and females in Australia. Int J Chron Obstruct Pulmon Dis. 2016;11:1097-1103. doi:10.2147/COPD.S103817

16. Kim J, Yoon HI, Oh Y-M, et al. Lung function decline rates according to GOLD group in patients with chronic obstructive pulmonary disease. Int J Chron Obstruct Pulmon Dis. 2015;10:1819-1827. doi:10.2147/COPD.S87766
17. Silvestre OM, Nadruz W, Querejeta Roca G, et al. Declining lung function and cardiovascular risk: the ARIC Study. J Am Coll Cardiol. 2018;72(10):1109-1122. doi:10.1016/j.jacc.2018.06.049

18. Sakhamuri S, Lutchmansingh F, Simeon D, et al. Reduced forced vital capacity is independently associated with ethnicity, metabolic factors and respiratory symptoms in a Caribbean population: a cross-sectional study. BMC Pulm Med. 2019;19(1):62. doi:10.1186/ s12890-019-0823-9

19. Luoto J, Pihlsgård M, Wollmer P, et al. Relative and absolute lung function change in a general population aged 60-102 years. Eur Respir J. 2019;53(3):3. doi:10.1183/13993003.01812-2017

20. Triebner K, Matulonga B, Johannessen A, et al. Menopause is associated with accelerated lung function decline. Am J Respir Crit Care Med. 2017;195(8):1058-1065. doi:10.1164/rccm.201605-0968OC

21. Griffith KA, Sherrill D, Siegel E, et al. Predictors of loss of lung function in the elderly: the Cardiovascular Health Study. Am J Respir Crit Care Med. 2001;163(1):61-68. doi:10.1164/ajrccm.163.1.9906089

22. Garcia-Aymerich J, Lange P, Benet M, et al. Regular physical activity modifies smoking-related lung function decline and reduces risk of chronic obstructive pulmonary disease. Am J Respir Crit Care Med. 2007;175(5):458-463. doi:10.1164/rccm.200607-896OC

23. Herrett E, Gallagher AM, Bhaskaran K, et al. Data resource profile: Clinical Practice Research Datalink (CPRD). Int J Epidemiol. 2015;44(3):827-836.

24. Quint JK, Mullerova H, DiSantostefano RL, et al. Validation of chronic obstructive pulmonary disease recording in the Clinical Practice Research Datalink (CPRD-GOLD). BMJ Open. 2014;4(7): e005540. doi:10.1136/bmjopen-2014-005540

25. Booker R. Vital Lung Function: Your Essential Reference on Lung Functional Testing. London: Class Health; 2008.

26. Rothnie KJ, Müllerová H, Smeeth L, et al. Natural history of chronic obstructive pulmonary disease exacerbations in a general practicebased population with chronic obstructive pulmonary disease. $\mathrm{Am}$ J Respir Crit Care Med. 2018;198(4):464-471. doi:10.1164/ rccm.201710-20290C

27. NICE. Chronic obstructive pulmonary disease in over 16s: diagnosis and management | guidance and guidelines. Available from: https:// www.nice.org.uk/guidance/cg101. Accessed November 12, 2020.

28. Rothnie KJ, Chandan J, Goss H, et al. Validity and interpretation of spirometric recordings to diagnose COPD in UK primary care. Int $J$ Chron Obstruct Pulmon Dis. 2017;12:1663-1668. doi:10.2147/COPD.S133891

29. Kesten S, Celli B, Decramer M, et al. Adverse health consequences in COPD patients with rapid decline in FEV1 - evidence from the UPLIFT trial. Respir Res. 2011;12(1):129. doi:10.1186/1465-9921-12-129

30. Mannino DM, Davis KJ. Lung function decline and outcomes in an elderly population. Thorax. 2006;61(6):472-477. doi:10.1136/ thx.2005.052449

31. Chien JW, Au DH, Barnett MJ, et al. Spirometry, rapid FEV 1 decline, and lung cancer among asbestos exposed heavy smokers. COPD. 2007;4(4):339-346. doi:10.1080/15412550701601340

32. Yohannes AM, Tampubolon G. Changes in lung function in older people from the English longitudinal study of ageing. Expert Rev Respir Med. 2014;8(4):515-521. doi:10.1586/17476348.2014.919226

33. Suzuki M, Makita H, Konno S, et al. Annual change in FEV1 in elderly 10-year survivors with established chronic obstructive pulmonary disease. Sci Rep. 2019;9(1):2073. doi:10.1038/s41598-019-38659-8

34. Vestbo J, Anderson JA, Brook RD, et al. Fluticasone furoate and vilanterol and survival in chronic obstructive pulmonary disease with heightened cardiovascular risk (SUMMIT): a double-blind randomised controlled trial. Lancet. 2016;387(10030):1817-1826. doi:10.1016/S0140-6736(16)30069-1

35. Lee HY, Choi SM, Lee J, et al. Effect of tiotropium on lung function decline in early-stage of chronic obstructive pulmonary disease patients: propensity score-matched analysis of real-world data. Int J Chron Obstruct Pulmon Dis. 2015;10:2185-2192. 
36. Fletcher C, Peto R. The natural history of chronic airflow obstruction. Br Med J. 1977;1(6077):1645-1648. doi:10.1136/bmj.1.6077.1645

37. Anthonisen NR, Connett JE, Murray RP. Smoking and lung function of Lung Health Study participants after 11 years. Am J Respir Crit Care Med. 2002;166(5):675-679. doi:10.1164/rccm.2112096

38. Tashkin DP, Goodin T, Bowling A, et al. Effect of smoking status on lung function, patient-reported outcomes, and safety among COPD patients treated with glycopyrrolate inhalation powder: pooled analysis of GEM1 and GEM2 studies. Respir Res. 2019;20(1):135. doi:10.1186/s12931-019-1112-0

39. Bossé R, Sparrow D, Rose CL, Weiss ST. Longitudinal effect of age and smoking cessation on pulmonary function. Am Rev Respir Dis. 1981;123(4):378-381.

40. Celli BR, Thomas NE, Anderson JA, et al. Effect of pharmacotherapy on rate of decline of lung function in chronic obstructive pulmonary disease. Am J Respir Crit Care Med. 2008;178(4):332-338. doi:10.1164/rccm.200712-1869OC

41. Becklake MR, Kauffmann F. Gender differences in airway behaviour over the human life span. Thorax. 1999;54(12):1119-1138. doi:10.1136/thx.54.12.1119

42. Kanner RE, Connett JE, Altose MD, et al. Gender difference in airway hyperresponsiveness in smokers with mild COPD. The Lung Health Study. Am J Respir Crit Care Med. 1994;150(4):956-961. doi:10.1164/ajrccm.150.4.7921469

43. Dransfield MT, Washko GR, Foreman MG, et al. Gender differences in the severity of CT emphysema in COPD. Chest. 2007;132 (2):464-470. doi:10.1378/chest.07-0863

44. Bestall JC, Paul EA, Garrod R, et al. Usefulness of the Medical Research Council (MRC) dyspnoea scale as a measure of disability in patients with chronic obstructive pulmonary disease. Thorax. 1999;54(7):581. doi:10.1136/thx.54.7.581

45. NICE. Chronic obstructive pulmonary disease in over 16s: diagnosis and management. 2018. [cited March 15, 2018]; Available from: https://www.nice.org.uk/guidance/ng115. Accessed November 12, 2020.

46. Tantucci C, Modina D. Lung function decline in COPD. Int J Chron Obstruct Pulmon Dis. 2012;7:95-99. doi:10.2147/COPD.S27480

47. Jankowich MD, Rounds SIS. Combined pulmonary fibrosis and emphysema syndrome: a review. Chest. 2012;141(1):222-231. doi:10.1378/chest.11-1062

48. Burney PG, Hooper R. Forced vital capacity, airway obstruction and survival in a general population sample from the USA. Thorax. 2011;66(1):49-54.

49. Mannino DM, Buist AS, Petty TL, Enright PL, Redd SC. Lung function and mortality in the United States: data from the first national health and nutrition examination survey follow up study. Thorax. 2003;58(5):388. doi:10.1136/thorax.58.5.388
50. Koskela J, Katajisto M, Kallio A, et al. Individual FEV 1 trajectories can be identified from a COPD cohort. COPD. 2016;13(4):425-430. doi:10.3109/15412555.2015.1043423

51. Loh CH, Genese FA, Kannan KK, et al. Spirometry in hospitalized patients with acute exacerbation of COPD accurately predicts post discharge airflow obstruction. Chronic Obstr Pulm Dis. 2018;5 (2):124-133. doi:10.15326/jcopdf.5.2.2017.0169

52. Seemungal TAR, Donaldson G, Bhowmik A, et al. Time course and recovery of exacerbations in patients with chronic obstructive pulmonary disease. Am J Respir Crit Care Med. 2000;161 (5):1608-1613. doi:10.1164/ajrccm.161.5.9908022

53. Sun Y, Milne S, Jaw JE, et al. BMI is associated with FEV1 decline in chronic obstructive pulmonary disease: a meta-analysis of clinical trials. Respir Res. 2019;20(1):236. doi:10.1186/s12931-019-1209-5

54. Bottai M, Pistelli F, Di Pede F, et al. Longitudinal changes of body mass index, spirometry and diffusion in a general population. Eur Respir J. 2002;20(3):665. doi:10.1183/09031936.02.01282001

55. Chen Y, Horne SL, Dosman JA. Body weight and weight gain related to pulmonary function decline in adults: a six year follow up study. Thorax. 1993;48(4):375. doi:10.1136/thx.48.4.375

56. Lahousse L, Seys LJM, Joos GF, et al. Epidemiology and impact of chronic bronchitis in chronic obstructive pulmonary disease. Eur Respir J. 2017;50(2):1602470. doi:10.1183/13993003.02470-2016

57. Allinson JP, Hardy R, Donaldson GC, et al. The presence of chronic mucus hypersecretion across adult life in relation to chronic obstructive pulmonary disease development. Am J Respir Crit Care Med. 2016;193(6):662-672. doi:10.1164/rccm.201511-2210OC

58. Johannessen A, Eagan TML, Omenaas ER, et al. Socioeconomic risk factors for lung function decline in a general population. Eur Respir J. 2010;36(3):480-487. doi:10.1183/09031936.00186509

59. Hegewald MJ, Crapo RO. Socioeconomic status and lung function. Chest. 2007;132(5):1608-1614. doi:10.1378/chest.07-1405

60. Jackson B, Kubzansky LD, Cohen S, Weiss S, Wright RJ. A matter of life and breath: childhood socioeconomic status is related to young adult pulmonary function in the CARDIA study. Int $J$ Epidemiol. 2004;33(2):271-278. doi:10.1093/ije/dyh003

61. Fortis SA-O, et al., Combined forced expiratory volume in 1 second and forced vital capacity bronchodilator response, exacerbations, and mortality in chronic obstructive pulmonary disease. Ann Am Thorac Soc. $2019 ; 16(7): 826-835$.

62. Nissen F, Morales DR, Mullerova H, et al. Concomitant diagnosis of asthma and COPD: a quantitative study in UK primary care. $B r J$ Gen Pract. 2018;68(676):e775-e782. doi:10.3399/bjgp18X699389

63. Elbehairy AF, Whittaker H, Quint JK, et al. S49 Identifying patient suitability for lung volume reduction - estimation of gas trapping from spirometry. Thorax. 2018;73(Suppl 4):A30.

\section{Publish your work in this journal}

The International Journal of COPD is an international, peer-reviewed journal of therapeutics and pharmacology focusing on concise rapid reporting of clinical studies and reviews in COPD. Special focus is given to the pathophysiological processes underlying the disease, intervention programs, patient focused education, and self management protocols. This journal is indexed on PubMed Central, MedLine and CAS. The manuscript management system is completely online and includes a very quick and fair peer-review system, which is all easy to use. Visit http://www.dovepress.com/testimonials.php to read real quotes from published authors. 